\title{
DEPO TASARIMI VE YERLEŞIMI: BİR GERÇEK HAYAT UYGULAMASI
}

\author{
Peral TOKTAŞ PALUT*, Fırat OKÇUOĞLU**
}

\section{ÖZ}

Etkin bir depo tasarımı ve yerleşimi firmaların operasyon maliyetlerini önemli ölçüde azaltmaktadır. Bu çalışmada, bir beyaz eşya firmasına ait depo tasarımı ve yerleşimi problemi ele alınmıştır. Çalışmanın ilk aşamasında, deponun tasarımını önemli ölçüde etkileyeceği için kullanılacak olan forkliftlerin seçimi yer almaktadır. Bu amaçla, forklift seçim kriterleri belirlenmiş; Analitik Hiyerarşi Süreci ile kriterlerin ağırlıkları hesaplanmış; ve TOPSIS yöntemi kullanılarak en uygun forklift alternatifi belirlenmiştir. Ardından, deponun kısıtları da göz önünde bulundurularak depolama alanları tasarlanmış; ve beklenen toplam taşıma mesafelerini en aza indirgemek amacıyla bir matematiksel model kurulmuştur. Matematiksel model çözülerek optimal sonuç elde edilmiş ve ürün gruplarının atanacağı depolama alanları belirlenmiştir.

Anahtar kelimeler: Depo tasarımı, Depo yerleşimi, Matematiksel model, Analitik Hiyerarşi Süreci, TOPSIS

Makale Gönderim Tarihi: 14.06.2019 ; Makale Kabul Tarihi : 08.11.2019 Makale Türü: Araştırma DOI: $10.20854 /$ bujse .577992

* Sorumlu yazar: Doğuş Üniversitesi, Endüstri Mühendisliği Bölümü, 34722, İstanbul, TÜRKİYE (ppalut@dogus. edu.tr)

** İstanbul Ticaret Üniversitesi, Endüstri Mühendisliği Yüksek Lisans Öğrencisi, 34840, İstanbul, TÜRKIYE (firat. okcuoglu@istanbulticaret.edu.tr) 


\title{
WAREHOUSE DESIGN AND LAYOUT: A REAL-LIFE APPLICATION
}

\author{
Peral TOKTAŞ PALUT*, FIrat OKÇUOĞLU**
}

\begin{abstract}
An efficient warehouse design and layout helps to decrease the operation costs of a firm. This paper studies the warehouse design and layout problem of a white goods company. First, the forklift selection problem is considered since it affects the warehouse design considerably. Accordingly, forklift selection criteria are determined; their weights are calculated using the Analytical Hierarchy Process; and the best forklift alternative is determined by the TOPSIS method. Afterwards, storage locations are designed; and a mathematical model is constructed to minimize the expected total transportation distances. The optimal solution is obtained and product groups are assigned to storage locations.
\end{abstract}

Keywords: Warehouse design; Warehouse layout; Mathematical model; Analytical Hierarchy Process; TOPSIS. 


\section{Giriş}

Depo tasarımı ve yerleşimi depo yönetiminin önemli unsurlarından biri olup, etkin bir depo yerleşimi operasyon maliyetlerini önemli ölçüde azaltmaktadır. $\mathrm{Bu}$ nedenle, firmalar artan rekabet koşullarında depo tasarımı ve yerleşimine gittikçe daha fazla önem vermektedir. Bu çalışmada, mevcut deposunu yeni bir alana taşıyacak olan bir beyaz eşya firmasına ait depo tasarımı ve yerleşimi problemi ele alınmıştır.

Depo tasarımının önemli adımlarından biri, depoda kullanılacak olan elleçleme ekipmanlarının seçimidir. Örneğin, depoda kullanılacak olan forkliftlerin çalışma koridor aralıkları, dönüş yarıçapları vb. faktörler farklılık göstermekte olup, bu unsurlar deponun tasarımını da önemli ölçüde etkilemektedir. $\mathrm{Bu}$ bağlamda, çalışmanın ilk aşamasında, çok kriterli karar verme yöntemlerinden Analitik Hiyerarşi Süreci ve TOPSIS (Technique for Order Preference by Similarity to an Ideal Solution) yöntemleri ile depoda kullanılacak olan forklift modeli belirlenmiştir. Forklift seçimi yapıldıktan sonra, deponun kısıtları da göz önünde bulundurularak depolama alanları tasarlanmıştır. Tasarımın tamamlanmasının ardından, depolanacak olan ürünlerin depodaki yerleşimlerinin belirlenmesi için bir matematiksel model kurulmuştur.

Literatürdeki çalışmalar incelendiğinde (Koster ve diğ., 2007), bu amaçla kurulan matematiksel modellerin taşıma mesafelerini enküçüklemek; depo alanı kullanımını enbüyüklemek; ekipman kullanımını enbüyüklemek; tüm ürünlere ulaşılabilirliği enbüyüklemek vb. amaç fonksiyonlarına sahip olduğu görülmektedir. Bu çalışmada da, beklenen toplam taşıma mesafelerini enküçüklemek amacıyla bir matematiksel model kurulmuş ve optimal çözüm elde edilerek hangi ürün grubunun hangi depo alanına atanması gerektiği belirlenmiştir.

Çalışmanın ikinci bölümü, yayın taraması; üçüncü bölümü, çok kriterli karar verme yöntemleri ile forklift seçimi; dördüncü bölümü, matematiksel model; ve son olarak beşinci bölümü ise sonuçlardan oluşmaktadır.

\section{Yayın Taraması}

Literatürde depo tasarımı, yerleşimi, yönetimi vb. konuları kapsayan birçok çalışma bulunmaktadır.
$\mathrm{Bu}$ çalışmalar, stratejik ve operasyonel planlama; depo tasarımı (gerekli alanların belirlenmesi, bölümlerin yerleşiminin belirlenmesi, ekipmanların seçimi, vb.); insan kaynakları yönetimi (personelin çizelgelenmesi, ergonomi ve güvenlik konuları, vb.); teknoloji ve ekipman (otomasyon seviyesinin seçimi, uygun ekipmanların seçimi, uygun depo yönetim sisteminin seçimi, vb.); performans ölçme, değerlendirme ve iyileştirme; mal teslimi ve sevkiyat işlemlerinin planlanması; depolama (ürünlerin depolanacağı alanların belirlenmesi, ürünler için alan ihtiyaçlarının hesaplanması, depolama politikalarının belirlenmesi, vb.); çekme stratejileri; ve deponun diğer bölümler ile olan bağlantıları gibi farklı kategorilerde incelenebilir (Davarzani ve Norrman, 2015). Bu bölümde, çalışmanın temelini oluşturan depo tasarımı ve yerleşimi üzerine literatürde yapılmış olan belli başlı çalışmalara yer verilmiştir.

Larson (1997), sınıf-tabanlı stoklama politikasını temel atan bir depo yerleşim düzeni geliştirmiş ve modelin çözümü için sezgisel bir yöntem önermiştir. Yang (2001), sırt çantası probleminin çözümünde kullanılan algoritmaya benzer bir algoritma geliştirerek raf alanı yerleşim problemini çözmüştür. Önerilen sezgisel yöntemde, her bir ürünün satış karlılığının rafta kapladı $\breve{g ̆}_{1}$ alana oranına göre ürünlerin raflara dağıtımı yapılmıştır. Roodbergen ve Vis (2006), ortalama taşıma mesafelerini enküçüklemek amacıyla depo yerleşimi için bir model geliştirmiş ve farklı rotalama stratejilerini kıyaslamıştır. Önüt ve diğ. (2008), depo stratejileri, rafların tasarımı, üretim tipi, sözleşme çeşitleri gibi stratejik konuları ele almıştır. Bu çalışmanın amacı, yıllık taşıma maliyetlerini en aza indirecek çoklu-seviye depo raf yapılarını tasarlamaktır. Baker ve Canessa (2009), depo tasarımı için gerekli tüm aşamaları yapısal bir model aracılığıyla belirlemiştir. Sanei ve diğ . (2011), ürünlerin depolama alanlarına atanması problemini çözmek için, operasyonel bazı kısıtları da dikkate alan bir matematiksel model geliştirmiş ve modelin çözümü için bir algoritma önermiştir. Guerriero ve diğ . (2013) ise, bu problemi çok katlı bir depoya uyarlayarak, tekrarlı yerel arama tabanlı bir sezgisel yöntem ile modeli çözmüştür.

Öztürkoğlu ve diğ. (2014), yük depoları için farklı koridor tasarımları geliştirmiştir. Yaptıkları çalışma, geliştirmiş oldukları tasarımların geleneksel koridorlara nazaran \%5-12 oranında daha iyi performansa sahip olduğunu göstermektedir. 
Shqair ve Altarazi (2014), farklı depo parametrelerinin ve bu parametrelerin birbirleri ile olan etkileşimlerinin depodaki taşıma mesafelerini ne ölçüde etkilediğini araştırmak için istatistiksel bir çalışma yapmıştır. Sonuçlar, depoda sadece bir çapraz koridorun bulunmasının ve sınıf tabanlı bir depolama politikası uygulamanın taşıma mesafelerini azalttığını göstermektedir. Cardona ve di ̌̆. (2015), genel operasyon maliyetlerini en aza indirecek ve balık kılçı̆̆ı düzenine dayanan farklı tasarımlar geliştirmiştir. Pazour ve Carlo (2015), bir deponun tasarımının değiştirilmesi ve deponun yeniden organize edilmesi amaciyla bir matematiksel model kurmuş ve farklı sezgisel yöntemlerin etkinliklerini kıyaslamıştır. Zhang ve diğ. (2017), depo yerleşimi ve kapasiteli parti hacmi belirleme problemlerini entegre ederek bir gerçek hayat problemini ele almış; kurdukları matematiksel modelin çözümü için sezgisel bir yöntem önermiştir. Accorsi ve diğ. (2017), çevrim süresi, toplam maliyet ve karbon ayak izini eniyilemek için çok amaçlı bir matematiksel model geliştirerek bir depo tasarımı yapmıştır. Arnaout ve diğ. (2017), çoklu seviyeli bir depoda taşıma maliyetlerini enküu̧ükleyecek bir matematiksel model geliştirerek hangi ürünlerin hangi depolama alanlarına atanacağını belirlemiş ve modeli karınca kolonisi algoritması ile çözmüştür. Arnaout (2017) ise, aynı problemin çözümü için solucan optimizasyonu yöntemini kullanmıştır.

Depo tasarımı ve yönetimi ile ilgili daha detaylı yayın taraması Gu ve diğ. (2007; 2010), Davarzani ve Norrman (2015) ile Reis ve diğ. (2017)'de bulunabilir. Bu araştırmalarda özellikle vurgulanan konu, depo yönetimi alanında yapılan bilimsel çalışmalar ile gerçek hayat uygulamaları arasında önemli bir boşluk olmasıdır. Bu çalışma, bir gerçek hayat uygulaması olması açısından önemli bir yere sahiptir.

\section{3. Çok Kriterli Karar Verme Yöntem- leri ile Forklift Seçimi}

Depoda kullanılacak olan forkliftlerin çalışma koridor aralıkları, dönüş yarıçapları vb. faktörler farklılık göstermektedir. Bu bağlamda, çalıșmanın ilk aşamasında, deponun tasarımını önemli ölçüde etkileyeceği için kullanılacak olan forkliftlerin seçimi yer almaktadır. Çalışmada, forklift seçim kriterlerinin ağırlıklarının belirlenmesi için Analitik Hiyerarşi Süreci (Saaty, 1980); en uygun forklift alternatifinin seçilmesi için ise TOPSIS yöntemi (Hwang ve Yoon, 1981) kullanılmıştır. Çalışmanın aşamaları aşağıda özetlenmiştir:

\section{Adım 1:}

Analitik Hiyerarşi Süreci ile ikili karşılaştırma matrisinin oluşturulması ve normalize edilmesi

Çalışmanın ilk adımında, seçim kriterleri arasında ikili karşılaştırma matrisi oluşturulmuş ve bu matris Denklem (1) kullanılarak normalize edilmiștir. Burada, $a_{i k}$, kriterinin k kriterine göre önemini; $\mathrm{m}$, toplam kriter sayısını göstermektedir.

$$
\bar{a}_{j k}=\frac{a_{\beta k}}{\sum_{i=1}^{m} a_{k k}}
$$

Adım 2:

Analitik Hiyerarşi Süreci ile kriter ağırlıklarının hesaplanması

Birinci adımda elde edilen normalize değerler kullanılarak, Denklem (2) uyarınca seçim kriterlerinin ağırlıkları hesaplanmıştır.

$$
w_{j}=\frac{\sum_{l-1}^{m} \bar{a}_{j l}}{m}
$$

Adım 3:

TOPSIS yöntemi ile alternatifler ve kriterler arasında değerlendirme matrisinin oluşturulması ve normalize edilmesi

Analitik Hiyerarşi Süreci ile seçim kriterlerinin ağırlıkları belirlendikten sonra, en uygun alternatifin seçilmesi için TOPSIS yöntemi kullanılmıştır. $\mathrm{Bu}$ adımda, alternatifler ve kriterler arasında bir değerlendirme matrisi oluşturulmuş ve bu matris vektör normalizasyonu (Denklem (3)) uyarınca normalize edilmiştir. Burada, $\boldsymbol{x}_{i j}$, alternatifinin $\mathrm{j}$ kriterine göre aldığ sayısını göstermektedir.

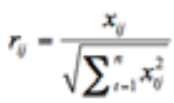

\section{Adım 4:}

TOPSIS yöntemi ile ağırlıklı normalize değerlerin hesaplanmasi

İkinci adımda elde edilen kriter ağırlıkları ile üçüncü adımda elde edilen normalize değerler çarpılarak, ağırlıklı normalize değerler hesaplanmıştır. 


$$
v_{i j}=w_{j} \times r_{i j}
$$

Adım 5:

TOPSIS yöntemi ile pozitif ve negatif ideal çözümlerin belirlenmesi

Bu adımda, Denklem (5) kullanılarak pozitif ideal çözümler ve Denklem (6) uyarınca negatif ideal çözümler belirlenmiştir. Burada, $J$. kar ölçütleri; $f^{\prime}$ ise maliyet ölçütleri kümesini göstermektedir.

$$
\begin{aligned}
& A^{*}=\left\{v_{i}^{*}, \ldots, v_{s}^{*}\right\}-\left\{\left(\max v_{q} \mid j \in J\right),\left(\min v_{q} \mid j \in J^{\prime}\right)\right\} \\
& A=\left\{v_{1}^{\prime}, \ldots, v_{-}^{-}\right\}=\left\{\left(\min v_{f} \mid j \in J\right),\left(\max v_{j} \mid j \in J^{\prime}\right)\right\}
\end{aligned}
$$

\section{Adım 6:}

TOPSIS yöntemi ile pozitif ve negatif ideal çözümlere olan uzaklıkların hesaplanması

Bu adımda, sırası ile Denklem (7) ve Denklem (8) kullanılarak, pozitif ve negatif ideal çözümlere olan uzaklıklar hesaplanmıştır.

$$
\begin{aligned}
& s_{i}^{\prime}=\sqrt{\sum\left(v_{0}-v_{j}^{-}\right)^{2}} \\
& s_{i}=\sqrt{\sum\left(v_{i}-v_{j}^{-}\right)^{2}}
\end{aligned}
$$

\section{Adım 7:}

TOPSIS yöntemi ile alternatiflerin ideal çözüme benzerliklerinin hesaplanması ve en uygun alternatifin seçilmesi

Çok kriterli karar verme yöntemleri ile forklift seçiminin son aşamasında, Denklem (9) uyarınca alternatiflerin ideal çözüme benzerlikleri hesaplanmış ve ideal çözüme benzerliği en yüksek olan alternatif seçilmiştir.

$$
C_{i}^{*}=\frac{S_{i}^{-}}{S_{i}^{-}+S_{i}^{*}}
$$

Forklift seçim kriterlerinin belirlenmesinde, literatür araştırması (Kulak, 2005; Hassan, 2010; Atanasković ve diğ., 2013) ve uzman görüşleri kullanılmıştır. Uzman görüşünden faydalanılan ekip, envanter planlama yöneticisi, depo şefi ve bir akademisyenden oluşmaktadır. Forklift seçim kriterleri, kapasite, çalışma süresi, kaldırma yük- sekliği, model yılı, ağırlık yük merkezi, toplam yükseklik, çatal uzunluğu ve fiyat olarak belirlenmiş olup; ağırlık yük merkezi ve fiyat, maliyet ölçütleridir. İlk olarak, Saaty'nin 1-9 önem skalas1 kullanılarak (Saaty, 1986) kriterler ikili olarak birbiri ile karşılaştırılmış ve ardından kriterlerin ağırlıkları belirlenmiştir. İkili karşılaştırma matrisi ve kriterlerin ağırlıkları sırasıyla Tablo 1 ve Tab-

\begin{tabular}{|c|c|c|c|c|c|c|c|c|}
\hline Sriknerer & Kipsis & $\begin{array}{l}\text { Caines: } \\
\text { stern }\end{array}$ & 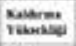 & Motet & 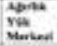 & Trung: & $\begin{array}{l}\text { Conil } \\
\text { Enathits }\end{array}$ & Now \\
\hline Kerouk: & 100 & क्या & 691 & 1,000 & Now & has & 100 & 2013 \\
\hline calis & 300 & 1800 & 1000 & $1 \mathrm{men}$ & 5000 & 1000 & $3 \mathrm{men}$ & 1900 \\
\hline velermes & 3000 & 1300 & 1000 & 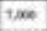 & sanes & 100 & 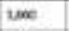 & $100=$ \\
\hline Maseth & 0.20 & Q.45 & b.61 & 1006 & 0.03 & 606 & ese & (2)1 \\
\hline $\begin{array}{l}\text { ven } \\
\text { vinten }\end{array}$ & am & $\alpha \leq \omega$ & ASW & 2006 & 1000 & 1000 & 208 & 150h \\
\hline 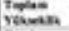 & axs & $a=0$ & $\sin$ & $3 x=$ & 1000 & 1000 & Nov & 200 \\
\hline Comblos & 1.200 & 2.33 & 5313 & 2006 & 3000 & 2000 & 1400 & 2123 \\
\hline$n_{2}=$ & 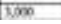 & कि & कि & $7 m$ & 100 & 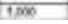 & $\pi \mathrm{s}$ & 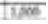 \\
\hline
\end{tabular}
lo 2'de verilmiştir. Tutarlılık oranı \%2,022 olarak hesaplanmış ve bu oran üst sınır olan \%10'dan düşük olduğu için modelin tutarlı olduğu sonucuna varılmıştır.

Tablo 1. İkili karşılaştırma matrisi

Tablo 2. Kriterlerin ağırlıkları

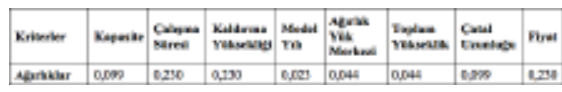

Firma ile yapılan görüşmeler sonucunda, Türkiye'nin önde gelen forklift firmalarından birine ait dört alternatif model seçilmiştir. Tüm modeller, enerji verimliliği sağlayan ve düşük gürültü seviyesine sahip akülü araçlar arasından belirlenmiştir. Modeller, yüksek kaldırma ve toplama kapasitesi; operatör için ergonomik ve güvenli çalışma koşulları ile öne çıkmaktadır.

Kriterlerin ağırlıkları belirlendikten sonra, dört forklift alternatifinden hangisinin en uygun olduğuna karar vermek için TOPSIS yöntemi kullanılmıştır. Bu amaçla, belirlenen tedarikçinin sunduğu dört farklı modele ait veriler toplanmış ve vektör normalizasyonu uygulanarak Tablo 3'de verilen normalize değer tablosu elde edilmiştir.

Normalize değerlerin hesaplanmasının ardından, bir önceki adımda belirlenen kriter ağırlıkları kullanılarak normalize değerler ağırlıklandırılmıştır. Daha sonra, pozitif ideal $\left(\mathrm{A}^{*}\right)$ ve negatif ideal (A) çözümler belirlenmiş; pozitif ve negatif ideal çözümlere olan uzaklıklar (sırasıyla $\mathrm{S}^{*}$ ve $\mathrm{S}^{-}$) bulunmuştur. Son olarak, alternatif modellerin ideal çözüme benzerlikleri ( $\left.\mathrm{C}^{*}\right)$ hesaplanmış ve en uygun olan alternatif belirlenmiştir. 
Ağırlıklı normalize değerler, ideal çözümler, ideal çözüme olan uzaklıklar ve ideal çözüme benzerlikler Tablo 4'de özetlenmiştir.

Tablo 3. Normalize değer tablosu

\begin{tabular}{|c|c|c|c|c|c|}
\hline \multirow{2}{*}{ Kritarle } & \multirow{2}{*}{ Abrasser } & \multicolumn{4}{|c|}{ Abrivenent } \\
\hline & & Model: & Model: & Andel? & Mesal \\
\hline Kapecate & 2000 & 4000 & 9.4 & 0.50 & $a x$ \\
\hline Calanes sined & 1250 & 620 & wea & cost & aess \\
\hline Kalleme Valuestes & 200 & 0.518 & and & 06 & 900 \\
\hline Bhat ve & $\sin$ & SSOI & $\operatorname{ann}$ & $\operatorname{com}^{\infty}$ & $a s 0$ \\
\hline Abras ra rentest & Het & 1.96 & 200 & $2 \times 0$ & $a s e$ \\
\hline Toples vasein & wat & $0.5 \mathrm{~s}$ & aet & a, en & asea \\
\hline Conal tinatopi & $\mu m$ & esoss & $a x e$ & 6, 06 & $a$ ane \\
\hline not & 200 & asis & Mito & 0.06 & 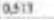 \\
\hline
\end{tabular}

Tablo 4. Ağırlıklı normalize değerler, ideal çözümler, ideal çözüme olan uzaklılar ve ideal çözüme benzerlikler

\begin{tabular}{|c|c|c|c|c|c|c|c|}
\hline \multirow{2}{*}{ Kriberler } & \multirow{2}{*}{ Nortaber } & \multicolumn{4}{|c|}{ Alwribenting } & \multirow{2}{*}{$f$} & \multirow{2}{*}{4} \\
\hline & & Nudet I & Meset 1 & Netat 3 & Modet 4 & & \\
\hline Kassulion & ans & a.801 & 0.06 & $\cos 1$ & 0001 & a)is & abe \\
\hline Catanesteres & Q206 & adose & 0.094 & b.34t & 0.14 & Q.144 & abs \\
\hline $\begin{array}{l}\text { Kaviom: } \\
\text { vasubsp }\end{array}$ & 0200 & a.118 & 0,10 & Q,117 & 0, & Q,13 & aion \\
\hline Matavt & ans & 0,002 & 0,002 & 0,002 & $\operatorname{axp} 2$ & ain2 & a.12 \\
\hline $\begin{array}{l}\text { Abrtik vak } \\
\text { Merkad }\end{array}$ & Qอน & $\operatorname{sen}$ & 0002 & bes & $0 \times 2$ & aes & acts \\
\hline Teptes Vilumbia & apen & ans & 0,001 & ons? & $\operatorname{ang} 2$ & aces & am: \\
\hline Cutal Dresthots & $0,00 \%$ & ans & 0,013 & onas & 0,013 & aoss & apon \\
\hline$n_{y=t}$ & 0216 & 0,016 & 0,004 & 0,200 & 0,118 & 0,064 & a.10 \\
\hline$s$ & & a.291 & 0,006 & 602 & Q,002 & & \\
\hline$s$ & & and & 0,000 & 6000 & ans & & \\
\hline e & & $a x a$ & $0 \cos 2$ & $\cos s$ & 0.744 & & \\
\hline
\end{tabular}

Tablo 4'den elde edilen sonuçlara göre, ideal çözüme olan benzerliği en yüksek olan forklift alternatifi olarak Model 3 seçilmiştir.

\section{Matematiksel Model}

Depoda kullanılacak olan forklift modelinin seçiminin ardından, firmanın yeni kuracağı deponun kısıtları da göz önünde bulundurularak depolama alanları tasarlanmıştır. Bunun için öncelikle, seçilen forkliftin manevra alanı dikkate alınarak koridor genişlikleri hesaplanmıştır. Toplam depo alanı $24.000 \mathrm{~m} 2$ 'dir ve deponun 17 giriş/çıkış noktası bulunmaktadır. Deponun elleçleme alanı, yangın söndürme dolapları vb. kısıtlar göz önüne alınarak depolama alanları tasarlanmış olup, toplam 1800 adet depolama alanı belirlenmiştir.

Firma, depoda, buzdolabı, çamaşır makinesi, bulaşık makinesi, fırın ve küçük ev aletleri olmak üzere beş farklı ürün grubunu adanmış stok politikası kullanarak stoklayacaktır. Ürünler için gereken depolama alanları sayısı sırası ile 335, 242, 61, 69 ve 175; stoğa giriş/stoktan çıkış sayıları ise $6120,8650,800,1155$ ve 3050 olarak belirlenmiştir. Deponun tüm giriş/çıkış noktaları eşit oranda kullanılmaktadır.
Çalışmanın bu bölümünde hangi ürün grubunun hangi depo alanına yerleştirileceğini belirlemek üzere bir matematiksel model kurulmuştur. Kullanılan indisler, notasyon ve matematiksel model (Tompkins ve diğ., 2010) aşağıda verilmiştir.

\section{Indisler}

$i$ : ürün grubu $(i=1, \ldots, n)$

$j$ : depolama alanı $(j=1, \ldots, m)$

$k$ : giriş/çıkış noktası $(k=1, \ldots, l)$

\section{Notasyon}

$$
\begin{aligned}
& x_{v}=\left\{\begin{array}{l}
1, t \text { äronin } j \text { depolama alanuna atanmagsa } \\
0, \text { aksi halde }
\end{array}\right. \\
& d_{A}=j \text { depolama alanindan } k \text { giriş/çiks noiktasına olan urakik (metre) }
\end{aligned}
$$

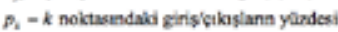

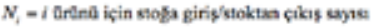

$$
\begin{aligned}
& S,-f \text { trind için gereken depolams alanlarnin sayst }
\end{aligned}
$$

\section{Matematiksel model}

$$
\begin{aligned}
& \min \sum \sum \frac{N}{s} \sum_{p_{1} d x_{j}} \\
& \dot{\sum}_{x_{i} \leq 1, \quad j=1,}, m \\
& \sum_{x_{v}}=3, \quad i=1, n \\
& x_{y}=0,1, i=1, \quad, x_{2} /=1, \quad, m
\end{aligned}
$$

Kurulan matematiksel model, beklenen toplam taşıma mesafelerini enküçüklemeyi amaçlamaktadır (10). İlk kısıt (11), bir depolama alanına en fazla bir ürünün atanmasını; ikinci kısıt (12), her bir ürününün tam olarak istenen sayıda depolama alanına atanmasını; üçüncü kısıt (13) ise $x_{L /}$ değişkenlerinin 0 ya da 1 değerini almasını sağlar. Matematiksel model GAMS programı ile çözülerek optimal çözüm elde edilmiş ve hangi ürün grubunun hangi depolama alanına atanacağı belirlenmiştir. Deponun nihai tasarımı Şekil 1'de verilmiştir.

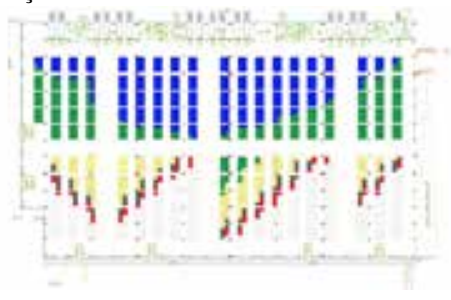

Şekil 1. Deponun nihai tasarımı* * Buzdolabı, yeşil; çamaşır makinesi, mavi; bulaşık makinesi, kırmızı; fırın, gri; küçük ev aletleri ise sarı renk ile temsil edilmiştir. 


\section{Sonuçlar}

$\mathrm{Bu}$ çalışmada, bir beyaz eşya firması için yeni bir depo tasarımı yapılmış ve depolama alanlarına atanacak ürünler belirlenmiştir. Bu bağlamda, deponun tasarımını önemli ölçüde etkileyeceği için öncelikle depoda kullanılacak forklift modeli belirlenmiştir. $\mathrm{Bu}$ amaçla, belirlenen forklift seçim kriterleri öncelikle Analitik Hiyerarşi Süreci yöntemi ile ağırlıklandırılmış; ardından TOPSIS yöntemi ile en uygun forklift modeli belirlenmiştir. Kullanılacak forklift modelinin belirlenmesinden sonra, forkliftin özelliklerine göre ve deponun kısıtları da göz önüne alınarak depolama alanları tasarlanmıştır. Ardından, beklenen toplam taşıma mesafelerini enküçüklemek amacıyla bir matematiksel model kurulmuş ve model çözülerek hangi ürün grubunun hangi depolama alanına atanacağı belirlenmiştir.

Gelecekteki çalışmalarda, farklı koridor ve depo tasarımları (örneğin, balık kılçığ ve Gue, 2009)) yapılarak elde edilen çözümler kıyaslanabilir. Bunun dişında, modele, envanter yönetimini ve taşıma ekipmanlarının kullanımını kolaylaştırmak için ek kısıtlar eklenerek problem sezgisel bir yöntemle çözülebilir. 


\section{KAYNAKLAR}

Accorsi, R., Bortolini, M., Gamberi, M., Manzini, R., Pilati, F., 2017. Multi-objective warehouse building design to optimize the cycle time, total cost, and carbon footprint, The International Journal of Advanced Manufacturing Technology, 92, 839-854.

Arnaout, J.-P., 2017. Worm optimization for the multiple level warehouse layout problem, Annals of Operations Research, DOI 10.1007/s10479-017-2683-0.

Arnaout, J.-P., ElKhoury, C., Karayaz, G., 2017. Solving the multiple level warehouse layout problem using ant colony optimization, Operational Research - An International Journal, DOI 10.1007/s12351017-0334-5.

Atanasković, P., Gajić, V., Dadić, I., Nikoličić, S., 2013. Selection of forklift unit for warehouse operation by applying multi-criteria analysis, Promet - Traffic\& Transportation, 25, 379-386.

Baker, P., Canessa, M., 2009. Warehouse design: A structured approach, European Journal of Operational Research, 193, 425-436.

Cardona, L. F., Soto, D. F., Rivera, L., Martinez, H. J., 2015. Detailed design of fishbone warehouse layouts with vertical travel, International Journal of Production Economics, 170, 825-837.

Davarzani, H., Norrman, A., 2015. Toward a relevant agenda for warehousing research: literature review and practitioners' input, Logistics Research, 8:1, DOI 10.1007/s12159-014-0120-1.

Gu, J., Goetschalckx, M., McGinnis, L. F., 2007. Research on warehouse operation: A comprehensive review, European Journal of Operational Research, 177, 1-21.

Gu, J., Goetschalckx, M., McGinnis, L. F., 2010. Research on warehouse design and performance evaluation: A comprehensive review, European Journal of Operational Research, 203, 539-549.

Guerriero, F., Musmanno, R., Pisacane, O., Rende, F., 2013. A mathematical model for the multi-levels product allocation problem in a warehouse with compatibility constraints, Applied Mathematical Modelling, 37, 4385-4398.

Hassan, M. M. D., 2010. A framework for selection of material handling equipment in manufacturing and logistics facilities, Journal of Manufacturing Technology Management, 21, 246-268.

Hwang, C. L. ve Yoon, K., 1981. Multiple Attribute Decision Making: Methods and Applications, Springer-Verlag, New York.

Kulak, O., 2005. A decision support system for fuzzy multi-attribute selection of material handling equipments, Expert Systems with Applications, 29, 310-319.

Koster, R., Le-Duc, T., Roodbergen, K. J., 2007. Design and control of warehouse order picking: A literature review, European Journal of Operational Research, 182, 481-501.

Larson, T. N., March, H., Kusiak, A., 1997. A heuristic approach to warehouse layout with class-based storage, IIE Transactions, 29, 337-348.

Meller, R. ve Gue, K., 2009. Aisle configurations for unit-load warehouses, IIE Transactions, 41, 171-182. 


\section{KAYNAKLAR}

Önüt, S., Tuzkaya, U. R., Doğaç, B., 2008. A particle swarm optimization algorithm for the multiple-level warehouse layout design problem, Computers and Industrial Engineering, 54, 783-799.

Öztürkoğlu, Ö., Gue, K. R. ve Meller, R. D., 2014. A constructive aisle design model for unit-load warehouses with multiple pickup and deposit points, European Journal of Operational Research, 236, 382-394.

Pazour, J. A. ve Carlo, H. J., 2015. Warehouse reshuffling: Insights and optimization, Transportation Research Part E: Logistics and Transportation Review, 73, 207-226.

Reis, A. C., Souza, C. G., Costa, N. N., Stender, G. H. C., Vieira, P. S., Pizzolato, N. D., 2017. Warehouse design: A systematic literature review, Brazilian Journal of Operations \& Production Management, 14, 542-555.

Roodbergen, K. J., Vis, I. F. A., 2006. A model for warehouse layout, IIE Transactions, 38, 799-811.

Saaty, T. L., 1980. The Analytic Hierarchy Process, McGraw-Hill, New York.

Saaty, T. L., 1986. Axiomatic foundation of the Analytic Hierarchy Process, Management Science, 32, 842-843.

Sanei, O., Nasiri, V., Marjani, M. R., Moattar Husseini, S. M., 2011. A heuristic algorithm for the warehouse space assignment problem considering operational constraints: with application in a case study, Proceedings of the 2011 International Conference on Industrial Engineering and Operations Management, Kuala Lumpur, Malaysia.

Shqair, M. ve Altarazi, S., 2014. A statistical study employing agent-based modeling to estimate the effects of different warehouse parameters on the distance traveled in warehouses, Simulation Modelling Practice and Theory, 49, 122-135.

Tompkins, J. A., White, J. A., Bozer, Y. A. ve Tanchoco, J. M. A., 2010. Facilities Planning, 4th Edition, John Wiley and Sons, Inc.

Yang, M. H., 2001. An efficient algorithm to allocate shelf space, European Journal of Operational Research, 131, 107-118.

Zhang, G., Nishi, T., Turner, S. D. O., Oga, K., Li, X., 2017. An integrated strategy for a production planning and warehouse layout problem: Modeling and solution approaches, Omega, 68, 85-94. 